\title{
Claude Habib, Galanterie française
}

\section{Fatima Pilone}

\section{(2) OpenEdition}

\section{Journals}

\section{Edizione digitale}

URL: http://journals.openedition.org/studifrancesi/9385

DOI: 10.4000/studifrancesi.9385

ISSN: 2427-5856

\section{Editore}

Rosenberg \& Sellier

\section{Edizione cartacea}

Data di pubblicazione: 1 juin 2008

Paginazione: $241-242$

ISSN: 0039-2944

\section{Notizia bibliografica digitale}

Fatima Pilone, «Claude Habib, Galanterie française», Studi Francesi [Online], 154 (LII | I) | 2008, online dal 30 novembre 2015, consultato il 09 janvier 2021. URL: http://journals.openedition.org/studifrancesi/ 9385 ; DOI: https://doi.org/10.4000/studifrancesi.9385

\section{Questo documento è stato generato automaticamente il 9 janvier 2021}

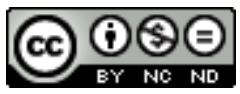

Studi Francesi è distribuita con Licenza Creative Commons Attribuzione - Non commerciale - Non opere derivate 4.0 Internazionale. 


\title{
Claude Habib, Galanterie française
}

\author{
Fatima Pilone
}

\section{NOTIZIA}

CLAUDE HABIB, Galanterie française, Paris, Gallimard, 2006, pp. 443.

1 Specialista di letteratura del xviII secolo e docente all'Università di Lille-III, Claude Habib percorre la storia della galanterie française, affermando che ancora oggi si parla di galanteria francese, come se qualcosa del carattere nazionale fosse legato a particolari gesti di cortesia. L'autrice segna la nascita di questo legame sotto il regno di Luigi XIV, un regno durante il quale tutti si sono voluti galanti, tanto da portare Claude Habib a dire che «le mot est partout». Da allora, la galanteria è passata dalla corte del re ai saloni borghesi, per arrivare oggi sino nei métros: «Des ruelles à la rue, le même respect se professe, le même charme se répand. La rue est le vivier de la galanterie...».

2 Il capitolo Belle Époque affronta il tema attraverso personaggi come Léon Blum e Cyrano de Bergerac, dove il galante viene colto di fronte ad una donna précieuse, all'insegna della delicatezza e della sottomissione dell'uomo, sancendo quindi la superiorità delle donne. Rousseau et la rupture romantique vede invece ne La Nouvelle Héloïse il libro che ha segnato una rottura, una rivoluzione sentimentale: Rousseau si riferisce spesso alla galanteria secondo connotazioni negative. In realtà, quello che cambia con Rousseau è l'appropriazione del sentimento amoroso da parte dell'individuo: i suoi amanti amano come se fossero i primi e gli unici. Rousseau segna il passaggio dall'era in cui l'amore galante era vissuto in società, secondo il linguaggio della condivisione, all'amore romantico, vissuto invece in solitudine. Il capitolo «L'âge galant: instauration, signification» ripercorre il regno di Luigi XIII, dove la galanteria diviene una forma ideale di aggregazione e di riunione dei due sessi, per giungere al culmine sotto il regno di Luigi XIV, fino alla fine dell'Ancien Régime. Secondo Claude Habib, per comprendere a pieno la galanterie bisogna passare attraverso la préciosité, dunque attraverso quel momento in cui le donne entrano a far parte della vita mondana ed imparano come inserirsi in una conversazione. «L'âge galant: libertés, fictions» si concentra 
essenzialmente sulla libertà femminile, una libertà che cresce man mano che anche il concetto di onore si traduce al femminile. In "Optimisme et plaisirs», Claude Habib racconta Luigi XIV e la sua corte, considerata il luogo dove le arti e l'amore hanno potuto esprimersi al meglio. Il monarca fece della galanteria verso le donne un elemento essenziale della sua monarchia, addolcendo lo stesso concetto di assolutismo, dove l'obbedienza non era politica bensì amorosa, «où il n'est d'autres pouvoir que celui que les femmes ont par nature sur le cœur des hommes». Infine, il capitolo «Les chances de la galanterie» prende in esame i gesti tradizionali della galanteria che, dopo essersi diffusi durante l'Ancien Régime negli ambienti aristocratici e borghesi, cominciarono poi ad esser visti male, per scomparire alla fine del secolo scorso. Nel Novecento il femminismo, con il suo rifiuto di tutte le regole che prima reggevano il rapporto uomo-donna, condanna anche la galanteria: l'attacco diviene feroce soprattutto negli anni Settanta. Il testo si conclude con la morte apparente della galanterie: oggi nessuno sarebbe fiero di essere galante, ma Claude Habib ritiene che questa qualità non sia realmente morta. La ritiene però congelata. 